\title{
Longshore Structure of Infragravity Wave Motions
}

\author{
R. A. Holman \\ School of Oceanography, Oregon State University \\ A. J. BOWEN \\ Department of Oceanography. Dalhousie University
}

\begin{abstract}
Synchronous runup records were collected from 14 locations spaced irregularly over a $7 \mathrm{~km}$ stretch of a low-slope beach. The significant runup height, herein defined as the significant vertical excursion of water level at the shoreline, was typically $2 \mathrm{~m}, 60 \%$ of the incident significant wave height at the breakpoint. The runup spectra were dominated by the energy at low frequencies, with $99.9 \%$ of the variance in motions with periods longer than $20 \mathrm{~s}$ and $83 \%$ for periods longer than $50 \mathrm{~s}$. A peak between 0.005 and $0.010 \mathrm{~Hz}$ was present in all spectra. Analysis of this band showed the motion to be a standing edge wave with wavelength between 5 and $10 \mathrm{~km}$ and significant edge wave height at the antinode of 1.3 $\mathrm{m}$, accounting for half of the local significant runup height. The edge wave period was approximately $140 \mathrm{~s}$ and the mode number in the range 3-7. An apparently linear sand bar was present $175 \mathrm{~m}$ offshore, roughly the same location as the first node of cross-shore velocity for the edge wave. While the edge wave could not have been the cause of the bar (a standing edge wave does not create a linear bar), the opposite may be true, with the bar potentially providing a topographic resonance. As the local headlands extend only a small fraction of the offshore distance of the edge wave, they are unlikely to be significant reflectors. The single rip current observed occurred at the edge wave node.
\end{abstract}

\section{INTRODUCTION}

Much of the dominant morphology on natural beaches is of large scale compared to the wave length of the incident waves. Linear sand bars may have typical offshore length scales of 50-100 m, crescentic bars can have longshore wavelengths of several hundred meters, and oblique or welded bars hundreds to thousands of meters. If we are to believe that these morphologies are a response to wave motions, then the corresponding wave motions must also be long, often falling in the infragravity frequency band (frequencies $0.03>f>0.003 \mathrm{~Hz}$ ).

Quantitative models have now been published which explain the generation of a number of common bar morphologies in terms of the drift velocities associated with edge waves. Crescentic bars were linked to a standing edge wave [Bowen and Inman, 1971], linear bars to a progressive edge wave [Bowen, 1981], and welded bars to two progressive edge wave modes of the same frequency [Holman and Bowen, 1982].

In fact, field measurement on low-slope and barred beaches often find infragravity motions to be dominant [Huntley, 1976; Sasaki and Horikawa, 1975; Wright et al., 1979; Holman, 1981; Huntley et al., 1981]. It would be of considerable interest if these motions proved to include a significant edge wave component.

Providing definitive field evidence for or against the presence of edge waves has proved difficult. This is primarily a result of the similarity of the alternative wave motions when viewed in a cross-shore transect, the normal direction to instrument nearshore field experiments. However, several recent experiments show proof of edge waves through analysis of the longshore behavior of the wave motions. Katoh [1981] used aerial photography of wave runup over a $200 \mathrm{~m}$ length of beach, terminated by a breakwater. His photographs were at

Copyright 1984 by the American Geophysical Union.

Paper number 4C0219.

0148-0227/84/004C-0219\$05.00 random time intervals, so he lacked frequency control. However, treating each photograph as a realization of a random process, he performed an empirical orthogonal function analysis (EOF) to determine the longshore covariance structure of the runup. The resulting sequence of eigenfunctions were sinusoidal in the longshore with antinodes at the break water. Huntley et al. [1981] used velocity data from a $500 \mathrm{~m}$ long linear curent meter array to prove the existence of low-mode infragravity edge waves on a low-slope beach.

This paper will discuss data from a much longer longshore array $(6 \mathrm{~km})$ which show the existence of very long-standing edge wave motions on the Oregon coast. The next section of the paper will discuss edge wave kinematics, particularly as applied to the recognition of edge wave modes in the field. Next we will discuss the experiment and then the results.

\section{Edge Wave Kinematics}

If depth is not a function of the longshore coordinate, $y$, then the velocity potential $\Phi(x, y, t)$ for a progressive edge wave is

$$
\Phi(x, y, t)=\frac{a_{n} g}{\sigma} \phi_{n}(x) \cos (k y-\sigma t)
$$

and for a standing edge wave is

$$
\Phi(x, y, t)=\frac{a_{n} g}{\sigma} \phi_{n}(x) \cos (k y) \cos (\sigma t)
$$

Here $x$ is the offshore coordinate measured positive seaward from the shoreline, $t$ is time, $g$ the acceleration due to gravity, $\sigma$ is the radial frequency ( $2 \pi$ divided by the period $T), k$ is the longshore wave number ( $2 \pi$ divided by the wavelength $L$ ), and $a_{n}$ is the amplitude of the $n$th mode. The offshore structure is contained in the term $\phi_{n}(x)$ which again is mode dependent.

For the case of a plane beach whose depth $h(x)=x \tan \beta$, where $\beta$ is the beach slope, Ursell [1952] showed the dispersion relation for edge waves to be

$$
\sigma^{2}=g k \sin (2 n+1) \beta
$$


This places a lower limit on $\boldsymbol{k}$ for edge waves

$$
k \geq \frac{\sigma^{2}}{g}
$$

and the highest $n$ for which (4) is true is called the cutoff mode. For $k<\sigma^{2} / g$ there exists a continuum of leaky modes which are not trapped to the shoreline.

A problem for field studies which emphasize the cross-shore structure of the infragravity motions has been the similarity of edge wave modes and leaky modes for small offshore distances (see, for instance, Figure 1 for the case of a plane beach). In contrast, studies in the longshore should be able to sort out different modes through their wave number (equation (3)) or should at least be able to distinguish between the leaky mode and edge wave regimes (equation (4)).

\section{Field Measurements}

The field experiment took place on a $7 \mathrm{~km}$ long, straight beach to the north of Heceta Head on the mid-Oregon coast. The subaerial portion of the headland extends about $100 \mathrm{~m}$ straight offshore, terminating the beach on the south end. To the north, the beach is terminated by a second basaltic headland, but with a much more subtle offshore protrusion (Figure 2). The foreshore slope was typically 0.04 . Subacqueous bathymetry data is sparse, consisting only of some short surveyed profiles from the month previous to the experiment. The "mean" beach slope was approximately 0.02 . The beach has a single, apparently linear, sand bar. The only survey line which reached the bar showed the bar crest to be $175 \mathrm{~m}$ offshore (for the tide height appropriate to the data run).

The wave data collected consisted of 14 synchronous time series of runup distributed unevenly over a $6 \mathrm{~km}$ longshore distance. The data were collected by time-lapse photography, using three synchronized movie cameras (one $16 \mathrm{~mm}$, two super 8) looking alongshore. A $40 \mathrm{~m}$ high rocky knoll, $5 \mathrm{~km}$ north of Heceta Head, provided an ideal location for two of the cameras, one looking north, the other south. A number of longshore locations were digitized from each of these films, the scale in the picture being taken either directly from previously surveyed, recognizable landmarks or interpolated from these points. The locations of the three cameras, labeled, A, B, C from north to south, and the positions of the digitized time series are shown in Figure 2. (Camera $C$ viewed the beach obliquely, allowing the digitization of only one range.) The run length was $70 \mathrm{~min}$ with a frame taken every $2 \mathrm{~s}$. Replicate digitizations of the same film by different operators showed errors on the variance to be about \pm 30 and $40 \%$ for ranges

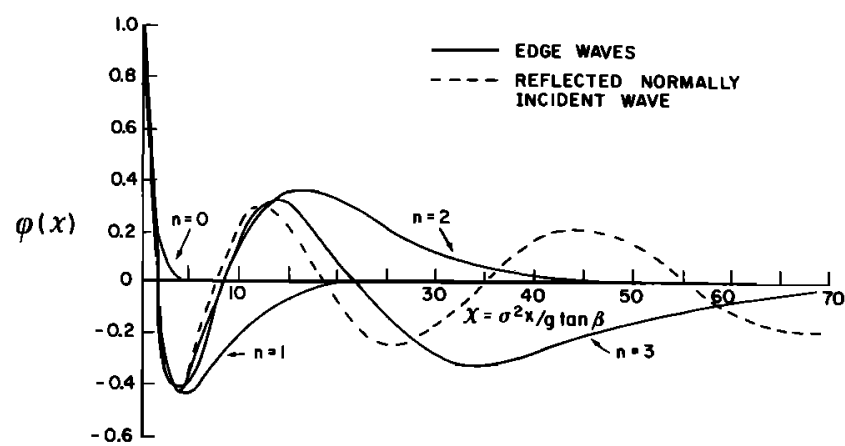

Fig. 1. $\phi(\chi)$ versus nondimensional offshore distance $\chi=\sigma^{2} x / g \beta$ for the lowest four edge wave modes and a reflected, normally incident wave.

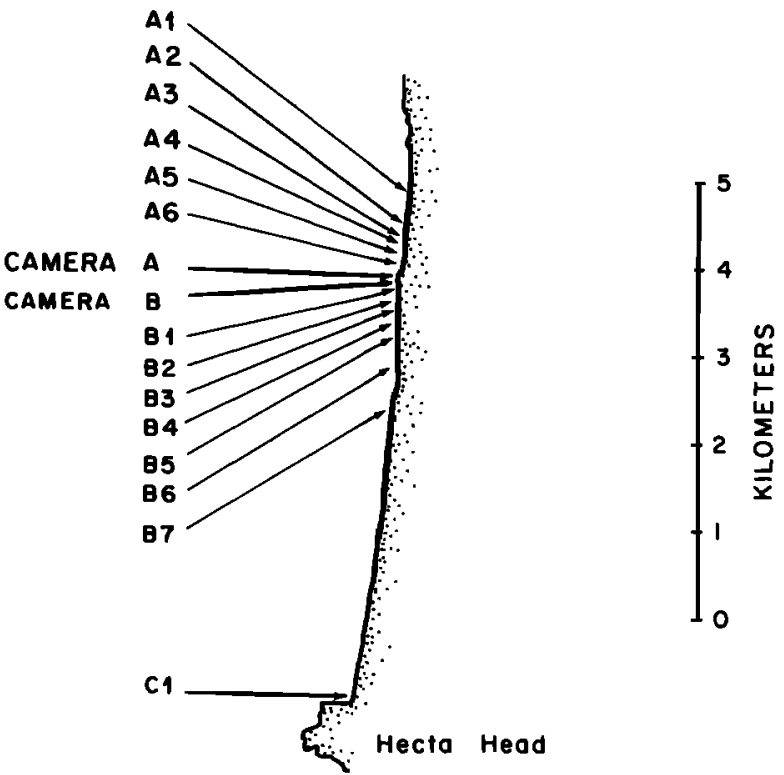

Fig. 2. Plan view of beach showing locations of cameras A, B, C and of digitized runup time series. Heceta Head terminates beach to the south; a smaller headland $\frac{1}{2} \mathrm{~km}$ to the north of run A1 terminates the beach to the north.

which were 250 and $500 \mathrm{~m}$ away from the camera, respectively (15 and $20 \%$ error on swash height). The spectral structure was well reproduced by all operators. A full description of the time-lapse photography technique and associated error estimates is contained in Holman and Guza [1984].

The data discussed below were obtained on October 9, 1980. The visually observed significant wave height, period, and angle of incidence were $3.5 \mathrm{~m}, 15.5 \mathrm{~s}$, and $8^{\circ} \mathrm{N}$ of normal, respectively. A longshore current of approximately $0.75 \mathrm{~m} \mathrm{~s}^{-1}$ flowed to the south. From the camera locations, only one rip current was visible, $100 \mathrm{~m}$ to the north of the knoll.

All runup time series have been converted from alongslope to the corresponding vertical component using the local beach profile. For two of the time series, B6 and B7, the closest profile was more than $500 \mathrm{~m}$ away. Transforming to the vertical runup signal, $\boldsymbol{R}_{v}$, could then alter the variance (and possibly the spectrum) if the foreshore profile changed alongshore. These two runs are not included in the general discussion which follows, but are included in the longshore structure analysis.

\section{ResULTS}

Figure 3 shows the time series from the 14 ranges. The low frequency nature of the runup is readily apparent. The longshore crest length of individual waves can also be seen. Table 1 includes summary statistics for the 12 data runs (neglecting B6 and B7). The mean variance for the 12 series $0.267 \mathrm{~m}^{2}$ with a standard deviation of $0.085 \mathrm{~m}^{2}$. The equivalent "significant runup height" (which is taken as $\mathbf{4}$ times the square root of the variance and assumes that the process is Gaussian) is $2.07 \pm 0.32 \mathrm{~m}$. This is $58 \%$ of the incident significant wave height, slightly less than the $71 \%$ ratio found by Guza and Thornton [1982]. There is some longshore structure to the variance with a minimum near A5 or A6.

Figure 4, a typical spectrum, confirms that the variance is completely dominated by waves with periods longer than the 


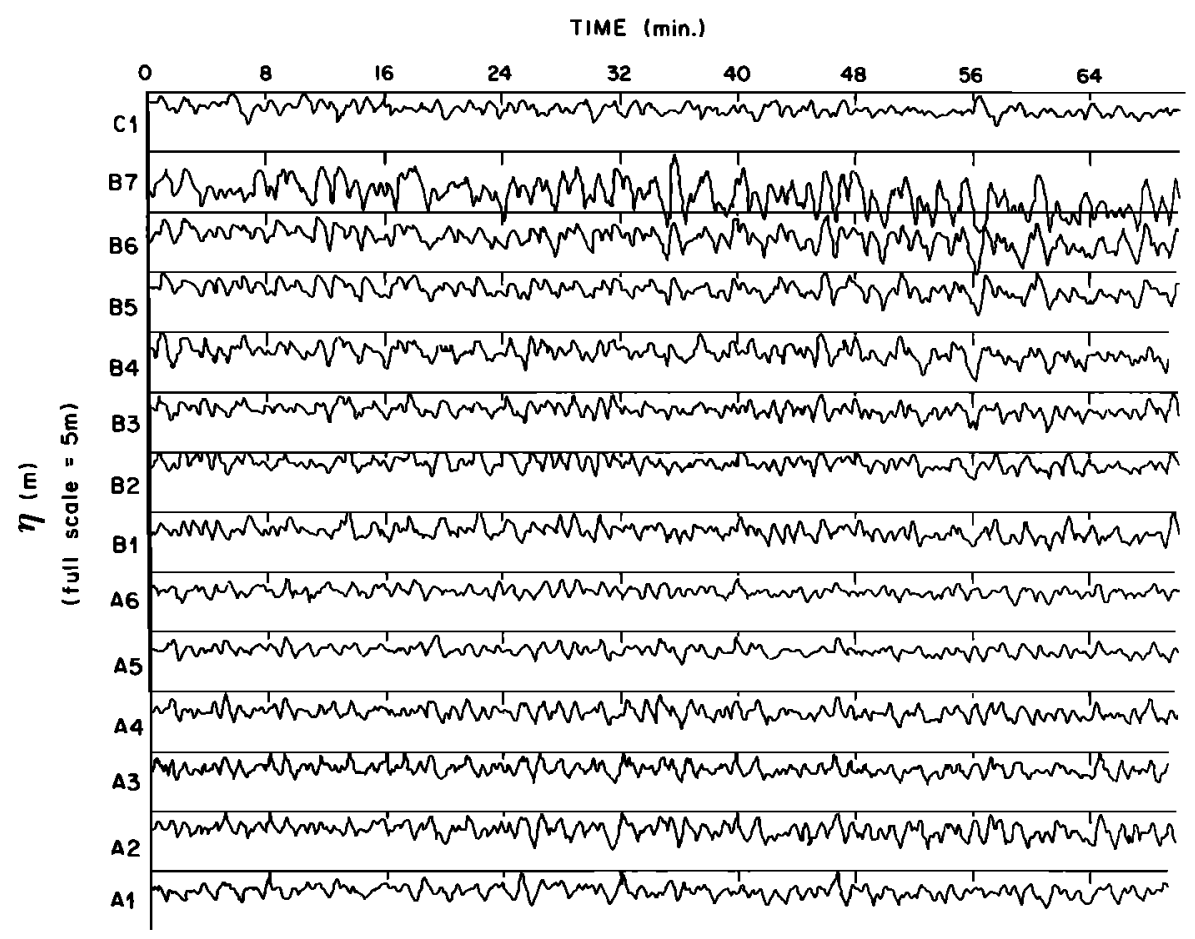

Fig. 3. Time series of sea surface elevation, $\eta$, for each of the 14 ranges. Ranges B6 and B7 provide useful phase information but are unreliable in variance due to lack of local beach profile data.

incident period. In fact, $99.9 \%$ of the total variance is carried by waves longer than $20 \mathrm{~s}$, and $83.5 \pm 3.4 \%$ is carried by waves longer than $50 \mathrm{~s}$. Table 1 shows the variation of this latter factor over the different series.

Figure 5 shows the spectra from all 12 longshore locations. The frequency axis now runs from 0.00 to $0.05 \mathrm{~Hz}$ reflecting the low frequency dominance. The spectra all look similar in shape and (within a half order of magnitude) in energy. This is reassuring since it means that a runup measurement at a single location such as is often taken in field experiments is representative of the beach as a whole. All spectra show energy decay at frequencies greater than $0.02 \mathrm{~Hz}$ and less than $0.005 \mathrm{~Hz}$. The very low frequency hill $(f<0.002 \mathrm{~Hz})$ seems to be largely related to the falling tide. The fall off in energy on the low frequency side of the infragravity band has implications for the infragravity wave dynamics, the forcing cannot be red.
Most of the finer structure of the spectra are not significant at the $95 \%$ confidence level and vary between spectra. However, between 0.005 and $0.010 \mathrm{~Hz}$, all spectra show a peak, suggesting the possibility of coherent motion over the entire beach length. Figure 6 shows the cross-spectral results between ranges $\mathrm{B} 3$ and $\mathrm{C} 1$. The peak between 0.005 and 0.010 $\mathrm{Hz}$ is significantly coherent at the $95 \%$ level despite the fact that the ranges are separated by $5 \mathrm{~km}$. The phase difference is $180^{\circ}$, suggesting a motion which is standing in the longshore.

The longshore structure of this band was analyzed by using frequency domain EOF analysis [Wallace and Dickenson, 1972; Wang and Mooers, 1977]. If the cross spectrum between two ranges $i$ and $j$ for a particular frequency band is given by

$$
U_{i j}=C_{i j}+i Q_{i j} \quad i, j=1, N
$$

where $C$ and $Q$ are the cospectral and quadspectral estimates

TABLE 1. Summary Statistics for the 12 Time Series

\begin{tabular}{ccccc}
\hline Range & $\begin{array}{c}\text { Total } \\
\text { Variance, } \\
\mathrm{m}^{2}\end{array}$ & $\begin{array}{c}\text { Variance for } \\
f \leq \mathbf{0 . 0 2} \mathbf{H z}, \\
\mathrm{m}^{2}\end{array}$ & $\begin{array}{c}\text { Percent } \\
\text { Age of } \\
\text { Variance for } \\
f \leq 0.02 \mathrm{~Hz}\end{array}$ & $\begin{array}{c}\text { Significant } \\
\text { Runup Height, } \\
f<0.02 ~ \mathbf{~ H z} \\
\mathrm{m}\end{array}$ \\
\hline A1 & 0.235 & 0.209 & 89 & 1.83 \\
A2 & 0.350 & 0.299 & 85 & 2.19 \\
A3 & 0.223 & 0.174 & 78 & 1.67 \\
A4 & 0.252 & 0.207 & 82 & 1.82 \\
A5 & 0.164 & 0.136 & 83 & 1.48 \\
A6 & 0.152 & 0.126 & 83 & 2.42 \\
B1 & 0.317 & 0.255 & 80 & 1.89 \\
B2 & 0.263 & 0.224 & 85 & 1.80 \\
B3 & 0.253 & 0.203 & 80 & 2.40 \\
B4 & 0.437 & 0.361 & 83 & 2.21 \\
B5 & 0.361 & 0.306 & 85 & 1.68 \\
C1 & 0.198 & 0.177 & 89 & $1.86 \pm 0.30$ \\
Average & $0.267 \pm 0.085$ & $0.223 \pm 0.071$ & $83.5 \pm 3.4$ & \\
\hline
\end{tabular}




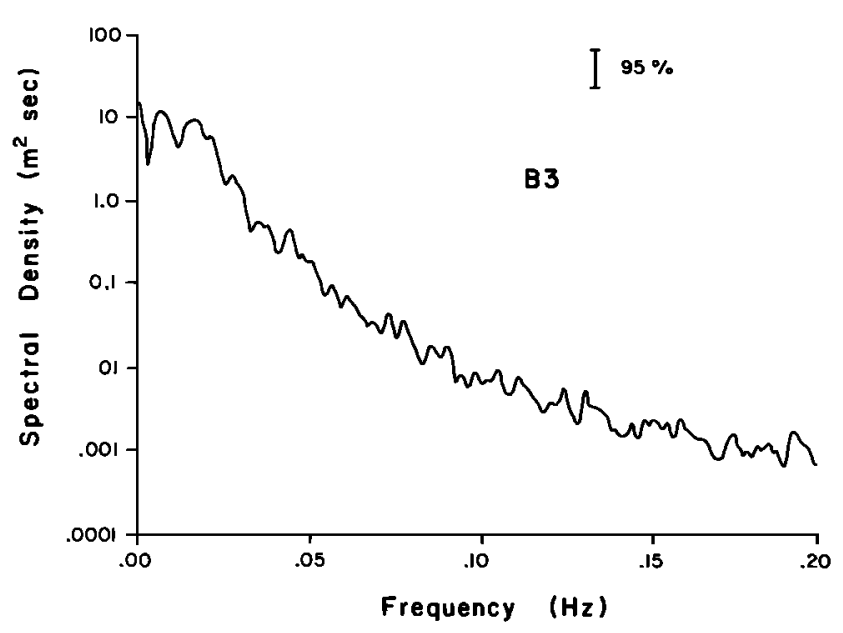

Fig. 4. Typical runup spectrum (B3) with 75 degrees of freedom.

and $N$ is the number of ranges, then the empirical orthogonal functions are the eigenvectors of $U_{i j}$. The eigenvectors will be complex and can be expressed in terms of amplitude and phase.

Figure 7 shows the longshore structure of amplitude and phase for the first eigenfunction from the frequency band $0.005-0.010 \mathrm{~Hz}$. The origin of longshore distance is arbitrarily taken at the farthest northern range. The amplitude structure is highly variable with an apparent node at $0.9 \mathrm{~km}$. The amplitude decreases from the apparent maximum at $2.5 \mathrm{~km}$ to the single point at $6.0 \mathrm{~km}$, although the lack of data precludes determining the existance of a second node based on amplitude alone.

The phase structure of the eigenvector proves the motion to be standing in the longshore. Phase is zero and constant to the north of the amplitude node at $0.9 \mathrm{~km}$, then switches suddenly to $180^{\circ}$ and constant to the south. The data point at $6.0 \mathrm{~km}$ indicates that phase has again switched to zero somewhere in the region of the beach where we have no data, a second longshore node. Note that the previously neglected data at B6 and $\mathrm{B} 7$, while of questionnable amplitude, show phase relations consistent with the rest of the data. The bold triangle, at $1.0 \mathrm{~km}$ on the figure, shows the location of cameras A and B

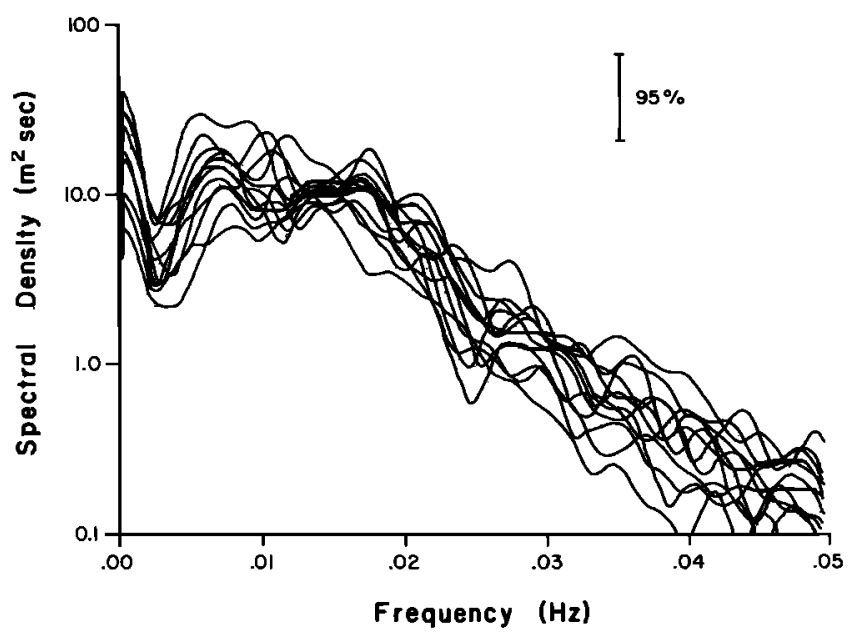

Fig. 5. Superposition of spectra ( 24 degrees of freedom) from all 12 longshore locations. Note that the maximum frequency is $0.05 \mathrm{~Hz}$.
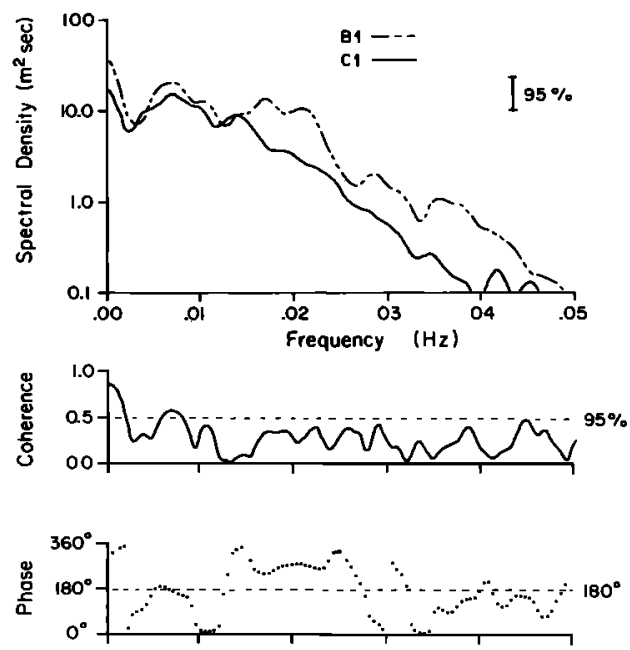

Fig. 6. Cross-spectral results between ranges B1 and C1. Estimates have 24 degrees of freedom.

on the knoll. The observation of the longshore node away from this site is reassuring, precluding any camera synchronization problems and showing that the knoll did not strongly interfere in the hydrodynamics.

The existence of a node in longshore structure is diagnostic of a standing wave motion. With only one node actually mapped, we cannot determine an exact wavelength. However, the existence of the second node somewhere in the region 2.5-6 km allows us to place limits on the wavelength. Assuming the position of the second node to be at minimum hallway between the first node and the $6.0 \mathrm{~km}$ point, and at maximum at the $6.0 \mathrm{~km}$ point, the full edge wave wavelength will be in the range $5-10 \mathrm{~km}$. From (4) the cutoff wavelength would be $30 \mathrm{~km}$, much longer than this observed wavelength, proving the motion to be a trapped edge wave. If we take a representative "mean" beach slope to be 0,02 and the wave period to be $140 \mathrm{~s}$ (the peak in coherence from cross spectra, Figure 6), the equivalent edge wave mode number will be between 3 and 7 ; that is the mode number is small, but not 0

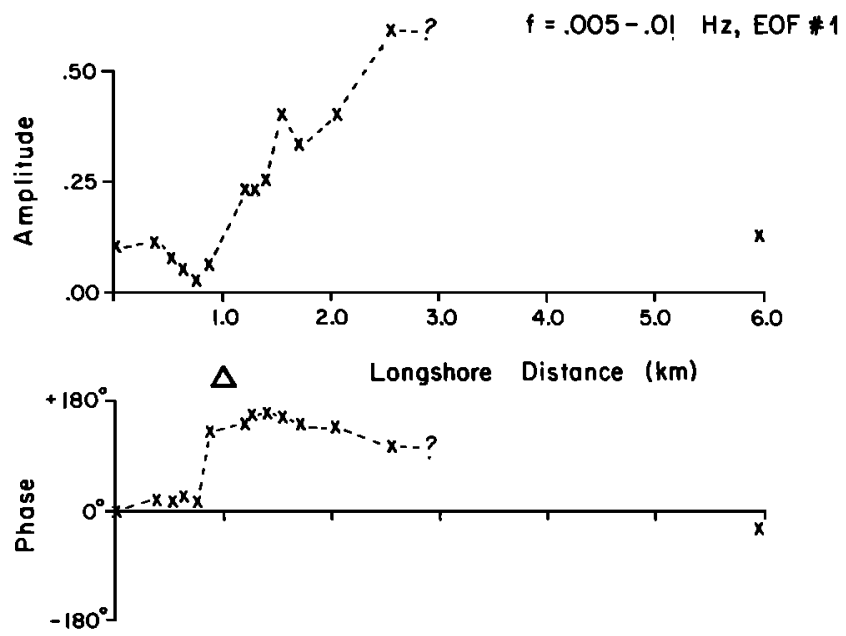

Fig. 7. First eigenfunction for the frequency band $0.005-0.010 \mathrm{~Hz}$ Both amplitude (top) and phase (bottom) are plotted as a function of longshore distance. Data points are indicated by crosses. The location of cameras A and B is shown by the bold triangle. Question marks indicate no data between 2.5 and $6.0 \mathrm{~km}$. 
and 1 (for the wave to have been a mode 1 , the mean beach slope would have to have been at least 0.055 , greater than the observed foreshore slope).

Holman and Bowen [1982] show that linear sand bars will be formed at a nondimensional offshore distance of $\chi=$ $\sigma^{2} x / g \beta=3$, where $\sigma$ is the frequency of the generating edge wave. These data indicate $\chi=1.8$ for the observed bar (at mid to high tide) and the $140 \mathrm{~s}$ period. The agreement is approximate. That it is not better is not surprising since we could hardly suggest that the observed wave motion generated the observed bar; a standing edge wave should not generate a linear bar. The approximate agreement may indicate some sort of topographic tuning by a pre-existing bar.

The simplest mechanism for producing a standing edge wave is reflection from longshore barriers. Reflection from Heceta Head to the south is hard to detect due to the lack of data, but there is little to suggest a local antinode. The headland to the north (at $-0.5 \mathrm{~km}$ ) is most definitely not acting as a reflector since it is too close to the node at $0.9 \mathrm{~km}$. (The beach slope would have had to reduce dramatically for the wavelength reduction. Such was not observed.) There is some question as to what constitutes a "significant" reflector for an edge wave. Huntley et al. [1981] discuss edge wave reflection, although in their case the reflector is a submarine canyon. For a mode 3 edge wave on a plane beach they show that at least $90 \%$ of the edge wave energy will lie seaward of $\chi=2$, the approximate offshore extent of Heceta Head. This suggests that Heceta Head is seen more as roughness by the edge wave and that any effective reflector should have much larger offshore extent.

The observation of a single rip current $100 \mathrm{~m}$ north of the rocky knoll is of particular interest. Sasaki [1977] suggested that standing infragravity motions may cause rip currents, and Sasaki and Horikawa [1975] showed field evidence which suggests that the rip currents may occur at edge wave antinodes (in sea surface elevation). We, on the other hand, find the rip current at the edge wave node.

From the frequency domain EOF analysis we can determine the amplitude of the edge wave motion by using the first eigenvalue, $\lambda_{1}=0.8145$. If we take range B4 and B5 as representing the antinode of the wave, we find the variance at the antinode associated with the first eigenvector to be $0.112 \mathrm{~m}^{2}$.

TABLE 2. Percentage of the Variance in the Band $0.005-0.010 \mathrm{~Hz}$ Explained by the First Two Eigenmodes for Each Longshore Location

\begin{tabular}{ccc}
\hline & \multicolumn{2}{c}{ Percent Variance Explained } \\
\cline { 2 - 3 } Range & First Mode & Second Mode \\
\hline A1 & 16 & 28 \\
A2 & 14 & 55 \\
A3 & 11 & 56 \\
A4 & 4 & 47 \\
A5 & 2 & 51 \\
A6 & 13 & 41 \\
B1 & 55 & 29 \\
B2 & 61 & 20 \\
B3 & 71 & 14 \\
B4 & 83 & 9 \\
B5 & 96 & 2 \\
B6 & 99 & 0 \\
B7 & 75 & 11 \\
C1 & 33 & 33 \\
\hline
\end{tabular}

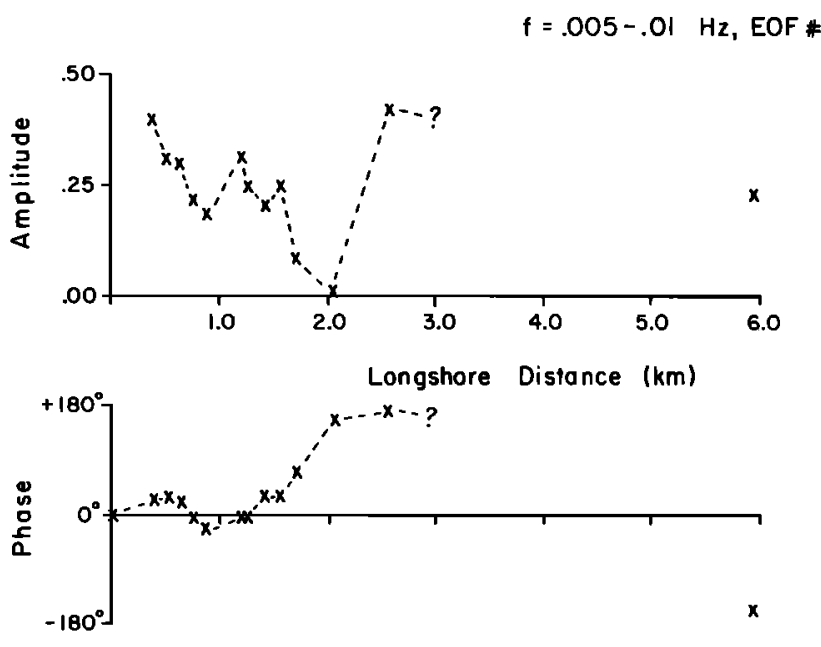

Fig. 8. Second eigenfunction for the frequency band $0.005-0.01 \mathrm{~Hz}$. This eigenfunction explains $17 \%$ of the variance in this band.

This is equivalent to a significant edge wave height, at the antinode, of $1.34 \mathrm{~m}$.

The first eigenvector explains $57 \%$ of the total variance for the 14 time series for the frequency band $0.005-0.010 \mathrm{~Hz}$. However, the percentage of the variance explained for individual series varies strongly, ranging from $2.5 \%$ for range A5 to over 95\% for ranges B5 and B6 (Table 2). The second eigenvector for this band, which explains $17 \%$ of the total variance for the 14 time series (eigenvalue $\lambda_{2}=0.235$ ), is plotted in Figure 8, and the percentage of variance explained for each longshore location is listed in Table 2. This eigenvector is most important in the northern ranges, near the node of the first mode. The amplitude and phase structure do not correspond to any obvious kind of wave motion.

Figures $9 a$ and $9 b$ show the first and second eigenvectors for the frequency band $0.01-0.015 \mathrm{~Hz}$. These vectors explain 53 and $28 \%$, respectively, of the total variance in the band (eigenvalues are 0.367 and 0.187 , respectively). The cross spectrum between $\mathrm{B} 1$ and $\mathrm{Cl}$ (Figure 6) had shown this band to be incoherent, suggesting that coherent process would only operate on shorter length scales. The first eigenvector supports this

TABLE 3. Percentage of the Variance in the Band 0.01-0.015 Hz Explained by the First Two Eigenmodes for Each Longshore Location

\begin{tabular}{ccc}
\hline & \multicolumn{2}{c}{ Percent Variance Explained } \\
\cline { 2 - 3 } Range & First Mode & Second Mode \\
\hline A1 & 3 & 41 \\
A2 & 1 & 94 \\
A3 & 0 & 96 \\
A4 & 1 & 74 \\
A5 & 0 & 51 \\
A6 & 6 & 30 \\
B1 & 1 & 13 \\
B2 & 8 & 37 \\
B3 & 21 & 15 \\
B4 & 50 & 11 \\
B5 & 94 & 4 \\
B6 & 96 & 1 \\
B7 & 94 & 3 \\
C1 & 14 & 24 \\
\hline
\end{tabular}


contention, showing a localized amplitude structure in the region south of the knoll. The second mode dominates north of the camera site and shows constant phase north of the knoll, a $180^{\circ}$ phase shift at the knoll, and a progressive phase shift south of the knoll. These modes suggest that the knoll exerts a significant hydrodynamic influence for this band, in. contrast to lower frequencies.

\section{Discussion}

Huntley et al. [1981] found progressive edge waves on a low-slope beach with mode 0 dominating the frequency band $0.006-0.011 \mathrm{~Hz}$, shifting to mode 1 in the band $0.015-0.025$ Hz. However, owing, to a limited array length and the nature of his analysis technique they could not analyze for highmode, low frequency motions or for standing edge wave motions. Thus we cannot say whether there is any fundamental difference between our datasets. In fact, Huntley et al. [1981] note suggestions in the data for the presence of standing edge waves which may be reflecting from the two large submarine canyons which penetrate close to shore in that area, an idea previously mentioned by Inman et al. [1976].

The possibility that large-scale topography may place important constraints on edge waves is an appealing one from the point of view of the data presented here. First, the headlands are too small to act as significant reflectors. Second, the bandwidth of the standing wave motion is somewhat large. In an attempt to increase the frequency resolution, a further analysis was run using frequency bands of $0.0005 \mathrm{~Hz}$. The phase plots of the eigenvectors showed the strong phase shift indicative of the standing wave motion in the band 0.007$0.008 \mathrm{~Hz}$, a $30 \%$ variation in wavelength. However, the Fourier estimates used in the analysis had only 4-6 degrees of freedom, so confidence in the analysis must be low. It is apparent that longer data records are required to adequately resolve these frequencies using this technique. If longshore constraints are being provided by large-scale inner shelf topography, it is unclear at this time what that topography is.

\section{ConClusions}

The suite of runup time series presented here show that runup on a relatively flat beach can become quite large $(2.0 \mathrm{~m}$ significant runup height in an incident swell estimated to be

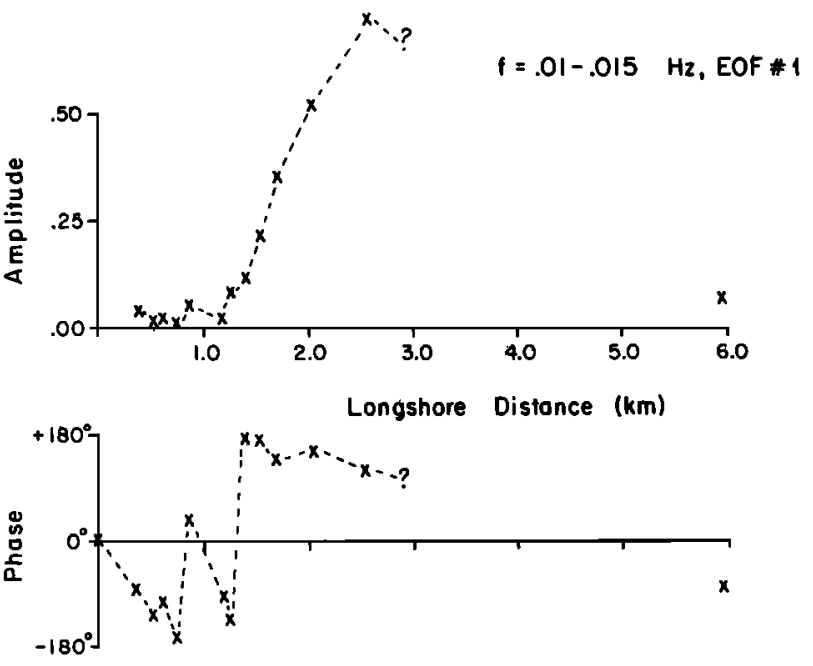

Fig. 9a. First eigenfunction for the frequency band $0.01-0.015 \mathrm{~Hz}$. This mode explains $44 \%$ of the variance.
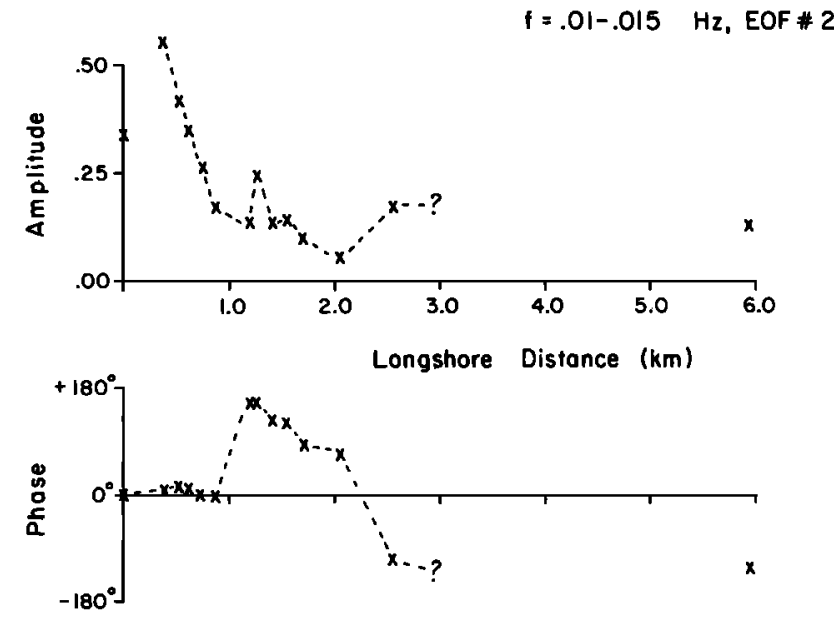

Fig. 9b. Second eigenfunction for the band $0.01-0.015 \mathrm{~Hz} ; 23 \%$ of the variance is explained by this mode.

$3.5 \mathrm{~m}$ at the breakpoint) and very low frequency (83\% of the variance contained in waves with periods longer than $50 \mathrm{~s}$ ). Spectra from 12 different longshore locations showed similar general structure decaying for frequencies greater than $0.02 \mathrm{~Hz}$ and less than $0.005 \mathrm{~Hz}$. Individual peaks between these frequency limits are not obviously correlated in the longshore with the exception of a peak between 0.005 and $0.010 \mathrm{~Hz}$ which is always present. Frequency domain EOF analysis showed the longshore structure of the energy to have a node in amplitude associated with a clear $180^{\circ}$ phase shift between two areas of larger amplitudes with constant phase. This structure is diagnostic of a longshore standing wave. While the exact wavelength could not be determined, it had to be between 5 and $10 \mathrm{~km}$, much shorter than the $30 \mathrm{~km}$ cutoff wavelength for leaky modes, indicating that the motion had to be a trapped edge wave. The equivalent edge wave mode number was between 3 and 7 , low but not 0 or 1 . The edge wave was of the same approximate period as would create the observed linear sand bar although a standing edge wave clearly could not have created a linear bar. The bar may exert some topographic control on the fluid motions. The observed headlands extended seaward only a fraction of the inferred offshore extent of the edge wave and were probably not significant reflectors. The longshore reflectors which did cause the standingness are unknown. A single rip current was noted at the observed node of the edge wave.

Acknowledgments. This work was supported by the Office of Naval Research, Coastal Sciences Branch, under contract NR 388-168. We would also like to thank Aage Gribskov for technical support and Pete Howd and Alan Morse for field assistance.

\section{REFERENCES}

Bowen, A. J., Simple models of nearshore sedimentation; beach profiles and longshore bars, The Coastline of Canada, edited by S. B. McCann, Pap. 80-10, Geol. Surv. of Canada, Ottawa, 1981.

Bowen, A. J., and D. L. Inman, Edge waves and crescentic bars, $J$. Geophys. Res., 76, 8662-8671, 1971.

Guza, R. T., and E. B. Thornton, Swash oscillations on a natural beach, J. Geophys. Res., 87, 483-491, 1982.

Holman, R. A., Infragravity energy in the surf zone, J. Geophys. Res., $86,6442-6450,1981$.

Holman, R. A., and A. J. Bowen, Bars, bumps, and holes: Models for the generation of complex beach topography, J. Geophys. Res., 87, $457-468,1982$. 
Holman, R. A., and R. T. Guza, Measuring runup on natural beaches, Coastal Eng., in press, 1984

Huntley, D. A., Long period waves on a natural beach, J. Geophys. Res., 81, 6441-6449, 1976.

Huntley, D. A., R. T. Guza, and E. B. Thornton, Field observations of surf beat, 1, Progressive edge waves, J. Geophys. Res., 86, 6451$6466,1981$.

Inman, D. L., C. E. Nordstrom, and R. E. Flick, Currents in submarıne canyons: An air-sea-land interaction, Ann. Rev. Fluid Mech., 8, 275-310, 1976.

Katoh, K., Analysis of edge waves by means of empirical eigenfunctions, Rep. Port Harbor Inst., 20, 3-51, 1981.

Sasaki, T., Field investigations of nearshore currents on a gently sloping bottom, Rep. 3, Nearshore Environ. Res. Center, Univ. of Tokyo, Tokyo, 1977.

Sasaki, T., and K. Horikawa, Nearshore current system on a gently sloping beach, Coaștal Eng. Jpn., 18, 123-142, 1975.

Ursell, F., Edge waves on a sloping beach, Proc. R. Soc. Ser. A, 214, 79-97, 1952 .
Wallace, J. M., R. E. Dickenson, Empirical orthogonal representation of time series in the frequency domain, I, Theoretical considerations, J. Appl. Meteorol., 11, 887-892, 1972.

Wang, D. P., and C. N. K. Mooers, Long coastal-trapped waves off the west coast of the United States, summer 1973, J. Phys. Oceanogr., 7, 856-864, 1977.

Wright, L. D., J. Chappell, B. G. Thom, M. P. Bradshaw, and P. Cowell, Morphodynamics of reflective and dissipative beach and inshore systems: Southeastern Australia, Mar. Geol., 32, 105-140, 1979.

A. J. Bowen, School of Oceanography, Oregon State University, Corvallis, OR 97331.

R. A. Holman, Department of Oceanography, Dalhousie University, Halifax, NS B3H 4J1, Canada.

(Received August 10, 1983;

revised January 31, 1984;

accepted February 1, 1984.) 